\title{
O tempo no agir docente: algumas reflexões para a formação de professores de línguas
}

\section{Time in Teaching: Some Reflections to Language Teacher Education}

Rosely Perez Xavier*

Universidade Federal de Santa Catarina

Florianópolis - Santa Catarina / Brasil

RESUMO: Este artigo discute a dimensão temporal da prática docente com base em duas formulações de tempo propostas por Deleuze (1998): Cronos e Aion. O objetivo é problematizar açōes pedagógicas à luz da temporalidade para trazer elementos que facultem a reflexão sobre a necessidade de se construir um tempo vivencial de qualidade na sala de aula de LE. O papel do supervisor de estágio é visto como fundamental para a construção desse tempo na formação inicial de professores.

PALAVRAS-CHAVE: ensino de LE; Cronos; Aion.

ABSTRACT: This article discusses the temporal dimension of foreign language teaching practice under two formulations of time proposed by Deleuze (1998): Chronos and Aion. The purpose is to problematize pedagogical actions under the notion of temporality in order to bring about elements that can promote reflection on the need to build a quality experiential time in the foreign language classroom. The role of the practicum supervisoris seen as fundamental to the construction of that time inpre-service language teaching education.

KEYWORDS: foreign language teaching; Chronos; Aion.

*rosely@ced.ufsc.br 


\section{Introdução}

"Class, I’ve got a lot of material to cover,

so to save time I won't be using vowels today.

Nw lts bgn, pls trn t pg 122.”

Fonte: <http://www.glasbergen.com/wp-content/gallery/educationand-teacher-cartoons/edu15.gif>.

Esta fala de professor retirada de um cartoon bem humorado, nos remete ao fator tempo no cotidiano do professor. É um dos elementos que afeta o nosso pensar e agir, exercendo efeito psicológico nos espaços em que atuamos e, muitas vezes, comprometendo a qualidade da interação, dependendo de como a prática pedagógica é condicionada a ele.

O presente trabalho busca analisar a estrutura temporal que o professor cria para si quando age metodologicamente, além de compreender as possíveis relações de causa e efeito dessa estrutura em sala de aula.

Para nortear a discussão, trago algumas situações de prática de ensino de professores de inglês, atuando em escolas básicas, que merecem um olhar reflexivo por parte dos formadores de professores, pois são eles os responsáveis por promoverem conscientização e momentos de reflexão sobre o tempo vivencial em sala de aula, isto é, em contextos onde os professores aprendizes irão atuar primordialmente.

O texto se inicia com duas leituras do tempo (Cronos e Aion) e, em seguida, discute algumas situações de ensino para ilustrar tempos desencontrados, tempos poupados, tempos desperdiçados e tempos enrijecidos. Para finalizar, considerações são feitas visando recuperar o papel do supervisor de estágio na formação inicial de professores.

\section{O tempo}

Poderíamos conceituar o tempo pelo viés da física, da astronomia ou da filosofia, mas é pelas nossas experiências e vivências que temos uma noção do que seja o tempo. Como salientaram Berger e Luckmann (2002, p. 44), “o mundo da vida cotidiana tem seu próprio padrão do tempo, que é acessível intersubjetivamente".

A temporalidade pode ser vista em seu aspecto cronológico, linear, ordenado e concatenado, como uma sequência de experiências de vida que não 
pode ser invertida. Trata-se de uma estrutura temporal coercitiva, segundo Berger e Luckmann (2002). Com base nessa visão de tempo, é possível compreendermos certas sequências de acontecimentos na sala de aula como, por exemplo, os estudantes não poderem realizar uma prova sem antes terem cumprido determinado programa ou conteúdo. Da mesma forma, essa estrutura temporal permite explicar certas sequências de conteúdos instrucionais nas aulas de línguas estrangeiras. Não se costuma ensinar a função "perguntar e responder as horas" sem antes abordar a função "cumprimentar" ou, ainda, a função "relatar fatos passados" sem antes "falar sobre fatos presentes" (onde mora, o que faz, o que gosta e prefere).

Essa linearidade que se costuma criar no espaço pedagógico nos permite especular sobre diversos temas, como a ordem dos conteúdos instrucionais, a temporalidade dos programas de ensino, o desenvolvimento dos saberes docentes (TARDIFF, 2006), a sequência das açôes pedagógicas, entre outras questôes relacionadas ao tempo do fazer e do ser docente, também denominado tempo linear ou tempo historicizado.

Há ainda outra forma de se ver o tempo, como um momento ou acontecimento intenso presente, não cronológico, que instaura um pensar sobre ele. Esse tempo independe de qualquer ordem numérica (primeiro isso, segundo aquilo etc.) e pode criar um novo início de uma lógica temporal própria. São, portanto, duas leituras do tempo que trago aqui, a de Cronos e a de Aion (DELEUZE, 1998). A primeira nos remete a uma sucessão de acontecimentos (tempo cronológico, numérico, longitudinal, vivenciado na continuidade), em que o presente absorve o passado e o futuro, "duas dimensōes relativas ao presente no tempo" (DELEUZE, 1998, p. 167). Trata-se de um presente vasto. A segunda leitura do tempo vincula-se ao momento vivido num determinado instante presente, em que o passado e futuro coexistem. É um tempo finito, não cronológico, transversal. Nas palavras de Deleuze (1998, p. 172-173), "[e]ste presente do Aion, que representa o instante, não é absolutamente como o presente vasto e profundo de Cronos", é um instante que "perverte o presente em futuro e passado insistentes" (p. 170). Em outras palavras, o presente em Aion não é alongado em passado e futuro como em Cronos, é um instante que, embora passado e futuro coexistam nele, simultaneamente, perverte o tempo cronológico que "insistentemente" nos faz sentir a existência de uma sequência alongada no tempo, que pode ser esperada e medida.

Como explica Oliveira, 
[...] enquanto em Cronos o presente é alongado em passado e futuro, com seus "agoras" situados no tempo e no espaço, em Aion o presente não existe, é o "instante" que divide ao infinito o tempo cronológico. Enquanto em Aion são os efeitos que se proliferam, em Cronos as causas prevalecem. Este se materializa nas coisas e causas, é circular e em único sentido - passado, presente, futuro -, aquele se faz no caos e nos efeitos, é reta com sentido simultâneo - passado e futuro ao mesmo tempo. (OLIVEIRA, 2007, p. 134).

Embora essa distinção possa parecer complexa, Deleuze (1998) afirma que Cronos e Aion representam duas leituras simultâneas do tempo. Assim sendo, é possível interpretar a temporalidade em seu aspecto diacrônico e sincrônico, bem como de forma longitudinal e transversal, respectivamente (HOY, 2009).

A gestão do tempo no espaço de sala de aula é de responsabilidade do professor, que determina o que vai ser feito, quando e como. É ele quem propóe o modo de viver o tempo das atividades de ensino e aprendizagem, muitas vezes, sob o tempo de Cronos e, outras, sob tempo de Aion. Isso significa dizer que as ações dos professores são construídas na continuidade de um tempo sucessivo (Cronos) e na intensidade do momento presente (Aion).

\section{As situações de ensino}

Para este trabalho, ações e decisões metodológicas de professores de inglês em formação inicial e em exercício são analisadas à luz da temporalidade. As situaçóes projetadas derivam de quatro fontes de dados. A primeira vem de minhas próprias observações de aulas de professores aprendizes em estágio supervisionado de inglês. Falo, portanto, como supervisora de estágio, num tempo específico da formação de professores de inglês, isto é, a oitava fase do curso de licenciatura em Letras/Inglês, quando os acadêmicos iniciam seu estágio supervisionado nas escolas, na configuração do currículo antigo. Ao longo de meus anos de orientação e supervisão de estágio, fiz um recorte de situações que aconteceram (e que ainda acontecem com frequência) para uma leitura do professor aprendiz sobre o tempo na ação que realiza.

A segunda fonte de dados decorre de observações de aulas realizadas por professores de inglês aprendizes, como atividade prática na escola básica em disciplinas de Metodologia de Ensino de Inglês e de Estágio Supervisionado. São, em geral, relatos descritivos, críticos e analíticos, encontrados nos relatórios finais de estágio supervisionado. 
A terceira fonte de dados é proveniente de relatos de estagiários sobre o desempenho do colega em prática docente. $O$ presente trabalho ainda conta com relatos de autoavaliação de estagiários em docência supervisionada. Trago, portanto, vários olhares que se entrecruzam sobre o fazer docente: $\mathrm{o}$ olhar do supervisor sobre o estagiário, o estagiário sobre o professor em exercício, o estagiário sobre o colega e o estagiário sobre si mesmo. Todos esses registros datam da década de 2000 e foram utilizados para recuperar situações que ilustram a organização e a construção do tempo pelo professor em sala de aula.

\section{Olhares sobre o tempo}

De forma muito sutil o tempo apressa as açóes dos professores, o que não significa dizer que o professor seja vítima do tempo, mesmo porque o tempo é individual (da mesma forma que é plural). É o professor quem organiza e gerencia o seu tempo pedagógico. Portanto, o tempo não é neutro, pois envolve decisões particulares de cada profissional para atingir os objetivos esperados. É nessa perspectiva que podemos presenciar tempos desencontrados, tempos poupados, tempos desperdiçados e tempos enrijecidos em sala de aula. As seçōes a seguir tratam de cada um desses tempos.

\section{Tempos desencontrados}

Referem-se a uma estrutura temporal em desalinho com o tempo de reflexão que se defende na educação crítica para a conscientização e formação da autonomia dos estudantes. Essa estrutura não costuma dar espaço para a reflexão dos alunos, apesar de estudiosos da educação (FREIRE, 1996; KUMARAVADIVELU, 1994 - entre outros) ressaltarem a necessidade e a importância de o professor fazer com que os alunos aprendam a pensar e a se expressar. O depoimento abaixo é de um professor aprendiz avaliando seu colega em momento de docência e traduz essa problemática.

Durante a aula temática, a Cristina mostrou familiaridade com o tema [...] Entretanto, ao fazer as perguntas previstas no plano, ela não esperou pela resposta dos alunos, sendo que após encaminhar as perguntas à turma, ela mesma antecipava as respostas, não fornecendo um tempo para que os alunos processassem as informações e elaborassem suas respostas. Creio que este foi um fato importante a ser refletido pela Cristina, uma vez que a participação dos alunos requer e depende deste tempo para o processamento das novas informações. (SANTOS; TAGLIARI; PETRIS, 2003, p. 19). 
O professor parece impor o seu tempo ao do aluno, que necessita raciocinar sobre o que ele escuta, lê, escreve, fala e faz com a língua. Sabemos que o tempo do professor não é o mesmo que o tempo do aluno, da mesma forma que o tempo do ensino não é, necessariamente, o tempo da aprendizagem ou, ainda, que o tempo de aprender não é o tempo da prova. São tempos diferentes que dependem da qualidade do instante presente que o professor constrói em sala de aula (tempo de Aion) e é essa consciência que o professor precisaria desenvolver no contexto da prática docente. Em outras palavras, cabe ao professor aguardar a fala dos alunos para promover o exercício da reflexão e, se necessário, fazer outros questionamentos e provocar estimulações cognitivas e interacionais.

Não muito diferente do depoimento acima, Carvalho (2006), em seu estudo de caso com uma professora efetiva de inglês em exercício há dezoito anos na escola básica, mostra que a professora, ficticiamente tratada como Clarice, costumava responder antecipadamente aos questionamentos que ela própria fazia à classe, o que demonstrava certa ansiedade para com o andamento da aula.

Clarice:Cidades turísticas. Give me some examples of tourist cities in Brazil. Give me some examples. Florianópolis is a tourist city, São Paulo, Rio de Janeiro, Minas Gerais. Ok, ó, tourist cities in Brazil. Florianópolis. (CARVALHO, 2006, f. 64).

Como explica Carvalho (2006), Clarice era consciente dessa atitude e atribuía sua preocupação ao tempo, pois tinha conteúdos para dar: "Uma falha minha: [...] Tentar fazer as perguntas ou explanaçôes com mais calma, sem olhar o tempo" (apud CARVALHO, 2006, f. 64).

Para muitos professores, o fator tempo é preponderante para o avanço do conteúdo instrucional. Trata-se de uma visão linear (Cronos) com vistas ao "futuro" (aos conteúdos seguintes) e ao progresso (ao avanço na matéria). Tais elementos costumam orientar a conduta de muitos professores, porém comprometem o instante presente (Aion), a reflexão dos alunos e a própria reflexão do professor, que deixa de aprender com os alunos sobre o que eles têm a dizer.

A pressa e a ansiedade em dar o conteúdo ou as atividades propostas tiram o direito de o aluno refletir sobre a língua estrangeira que está aprendendo. Um caso semelhante é de professores que costumam traduzir para o português o que dizem em inglês, aliviando a carga de processamento linguístico dos alunos e, ao mesmo tempo, roubando sua atenção do objeto de entendimento, isto é, a língua estrangeira. 
Após a atividade dos cartazes, a professora apresentou outras profissões. Ela mostrou um livro com figuras, dizendo:

$\mathrm{T}-$ Ok, please (ela espera silêncio). Thank you. I brought more occupations for you. Eu trouxe mais profissões para vocês. Pharmacist... here (ela aponta para a figura). Drugstore is farmácia; it is the place, lugar. He works in the drugstore. Gas station is posto de gasolina. (ARAÚJO; SEVERO, 2006, p. 12).

Carvalho (2006) também mostra que a tradução consecutiva é vista por alguns professores de inglês como solução garantida da compreensão, do engajamento dos alunos, do andamento da aula e da disciplina da classe. Com o uso do português, acredita-se que os alunos possam compreender as atividades mais facilmente, sendo possível assim "dar conta do conteúdo" e avançar no tempo. Ao impor esse modelo de temporalidade sobre os alunos, o professor rouba o tempo de raciocínio, de esforço e de compreensão da língua estrangeira pelos alunos.

Quando questionados sobre a questão do tempo roubado dos alunos, alguns professores aprendizes confessaram que o silêncio lhes causa certo desconforto, em particular quando fazem perguntas em inglês e nenhuma resposta imediata aparece. Por essa razão, preenchem rapidamente a lacuna do silêncio com as respostas, as traduções e o que for necessário para que a aula caminhe.

Nessa aula, assim como nas anteriores, minha ansiedade acabou atrapalhando visto que não esperei muito tempo pelas respostas dos alunos. Acredito que, com a experiência, o professor acaba se "acostumando" com o silêncio da classe. Mas para mim o silêncio era algo aterrorizante, pois achava que se os alunos não estavam respondendo era porque não tinham entendido o que eu havia perguntado. (JORGE; ABELAIRA, 2004, p. 70).

Sabemos que o silêncio do aluno pode representar uma série de coisas, como um tempo para o seu pensar sobre a resposta, sua incompreensão da pergunta, seu desconhecimento sobre a resposta correta, seu medo, sua insegurança ou timidez de responder. Cabe ao professor reflexão nesse momento; um tempo de análise online para poder decidir o que fazer, sem antecipar as respostas que deseja ouvir.

Dependendo do diagnóstico da situação, espera-se que o professor repita a sua pergunta, negocie ou calibre a sua fala na língua estrangeira, use paráfrases, gestos e incentive os alunos a responder, sem pressa de obter a resposta correta, 
pois o tempo pedagógico é uma construção social (FRAGO, 1998 apud OLIVEIRA et al., 2007).

No depoimento a seguir, a professora aprendiz repete sua pergunta quando percebe que os alunos não a respondem. Sem sucesso, admite que poderia ter usado outros meios para se fazer compreender e garantir a voz dos alunos.

Quando eu fui exemplificar a atividade, repeti a pergunta "Which picture illustrates bad smell?" várias vezes. Como os alunos não me davam nenhuma resposta, o que eu deveria ter feito era pedir o significado da pergunta. Além disso, eu deveria ter ajudado os alunos, perguntando "Which picture? 1, 2, 3, 4?". Faltou reflexão de minha parte neste momento. (JORGE; ABELAIRA, 2004, p. 46).

Situações como essas podem ser fruto de certa ansiedade do professor, sua descrença no aluno, sua falta de experiência e conhecimento na arte de questionar ou, ainda, sua postura centralizada, o que contribui para uma estrutura temporal que empobrece o engajamento dos alunos e a sua aprendizagem.

Nesse cenário de tempos desencontrados, Cronos se sobrepõe a Aion, pois o tempo no qual o professor quer chegar no presente (futuro) prevalece sobre o tempo que seria necessário para o aluno raciocinar e processar a língua estrangeira no instante presente.

\section{Tempos poupados}

O "controle do futuro" é passível de ocorrer se partirmos da noção de que, ao acelerarmos o presente, estamos avançando no desenvolvimento dos conhecimentos, das habilidades e das capacidades dos alunos. Novamente, o tempo Cronos se sobrepõe ao tempo Aion. Essa sobreposição acontece não somente quando o professor priva os alunos de refletirem, em tempo hábil, sobre as perguntas que faz, mas também quando cria uma estrutura temporal que poupa o esforço/trabalho do aluno e sua corresponsabilidade em sala de aula.

Algumas práticas docentes sugerem uma tendência do professor em "simplificar ou descomplexificar as atividades, apontando respostas, antecipandoas, exemplificando a primeira questão, fornecendo modelos, enfim, estratégias de ensino que possam facilitar o que parece ser difícil para os alunos na percepção do professor" (XAVIER, 2008, p. 192). São ações que visam a diminuir a possibilidade de fracasso dos alunos, pois o fracasso toma tempo do docente, e é esse tempo que 
o professor parece querer poupar para poder prosseguir com a matéria e cumprir o programa desejado, dando fluidez ao seu ensino.

Outra forma de poupar o tempo de sala de aula é quando o professor centraliza ações que poderiam ser compartilhadas com a coletividade, como na explicação das instruções de um exercício, por exemplo. Essa é uma ação que o professor costuma tomar para si, poupando os alunos dessa tarefa. Cabe a eles somente prestar devida atenção para poderem realizar a atividade.

Poderíamos, entretanto, pensar esse tempo como momento para o professor se descentralizar, atribuindo aos alunos o papel de explicar o que devem fazer. Dessa forma, oportunidades seriam criadas para a reflexão sobre o que eles leem na língua estrangeira, a organização de seu pensamento e a forma de se expressarem oralmente, com suas próprias palavras. Não se trata de pedir a eles a tradução das instruções, mas uma explicação cuidadosa, de modo que a voz do aluno seja ouvida, questionada e legitimada. Busca-se, assim, criar uma cultura do pensar, do fazer o aluno refletir sobre o que lê e, também, sobre o sentido do seu dizer, quando se depara com instruções de atividades na língua estrangeira. Seria, portanto, um tempo dedicado ao exercício do pensamento, da atenção, da autonomia e da cooperação entre os alunos, considerando a construção conjunta do entendimento das instruções pelo coletivo da classe.

Similarmente, observa-se que, na correção das atividades, o tempo de reflexão do aluno também é poupado. Muitos professores não costumam fazer questionamentos à turma, apenas verificam se as respostas estão certas ou erradas. Quando as respostas corretas não aparecem, o próprio professor as oferece gratuitamente. Essa prática novamente retrata um tempo centralizado no professor que, ao invés de indagar, instigar e conduzir os alunos a um olhar atencioso sobre as respostas apropriadas ou não, prefere avançar no tempo presente.

Para ilustrar, trago duas interações decorrentes de minhas anotações em supervisão de estágio, quando da correção de uma atividade de leitura (ANEXO A) conduzida por uma estagiária em prática docente. A atividade faz parte de um conjunto de tarefas que foram agrupadas sob o tema namoro e aplicadas em uma $\sigma^{\text {a }}$ série do ensino fundamental de uma escola pública.

[Questão 3]

Profa.: Por que o coelho se sente dessa maneira [desconfortável]?

Aluno: Porque ele não gosta de encontros.

Profa.: Ok, porque ele não gosta de encontros (e escreve no quadro). 
[Questão 5]

Profa.: Esse comentário [“Tá vendo? É por isso que eu detesto namorar”] expressa uma justificativa, um convite ou um aviso?

Aluno: Uma justificativa.

Profa.: Very good. (e anota a resposta no quadro).

Aparentemente as respostas fornecidas pelos alunos nas interações acima estão todas corretas; no entanto, questionamentos poderiam ser feitos para que o professor avaliasse o verdadeiro entendimento do aluno: "Por que o coelho não gosta de encontros?", "Por que esse comentário é uma justificativa?", "Por que essa alternativa e não a outra?". Tais indagações, após a confirmação da resposta correta, constroem um tempo de qualidade em sala de aula, um momento de reflexão sobre as respostas que, muitas vezes, são resultado de "chutes", cópia do colega e de intuiçôes.

Em outro momento de correção, dessa vez fruto de uma atividade de compreensão oral (ANEXO B), a professora aprendiz acata a resposta da classe (isto é, "Numa ponte") ao corrigir a pergunta: "Onde o casal está? Num bar?". $\mathrm{Na}$ cena do filme, o casal se encontra, realmente, em uma ponte; porém a resposta poderia se enquadrar num contexto maior de situação, já que uma ponte pode estar situada em um parque ou em outro lugar plausível. $\mathrm{Na}$ interação abaixo, a professora prefere complementar a resposta ("E essa ponte fica num parque") em vez de questionar a classe (ex.: "Mas onde vocês acham que fica essa ponte?"). Tal questionamento poderia trazer posicionamentos diversos, como "na floresta", "numa praça”, "num lugar grande", desencadeando outros questionamentos para o entendimento do contexto da situação.

\section{[Questão 1]}

Profa.: Onde o casal está? Num bar?

Alunos: Numa ponte.

Profa.: Ok, numa ponte (e escreve no quadro). E essa ponte fica num parque.

Pode-se dizer que o comportamento do professor costuma evidenciar formas de simplificação metodológica para poupar "gasto de tempo". Nos exemplos apresentados acima, a simplificação metodológica se manifesta em ações que (a) facilitam a realização das atividades para os alunos (ao resolver a primeira questão, ao dar exemplos/modelos de como fazer, ao fornecer uma lista de vocabulário, ao antecipar a resposta etc.); (b) centralizam o 
gerenciamento de sala de aula nas mãos do professor (ao explicar os enunciados, ao avaliar as respostas dos alunos, ao responder perguntas que poderiam ser encaminhadas para a classe, ao definir quem deve responder); e (c) apressam a correção das atividades (ao deixar de questionar ou explorar o sentido das respostas e as estratégias utilizadas pelos alunos). Tais ações nos remetem a uma dinâmica relacional linear entre professor e alunos, sem a criação de intersubjetividades. Segundo Tunes, Tacca e Bartholo Jr. (2005, p. 691), "para o professor empenhado em promover a aprendizagem de seu aluno, há o imperativo de penetrar e interferir em sua atividade psíquica, notadamente seu pensamento." Para isso, a meu ver, deve-se aproveitar o tempo para realizar mediações pedagógicas que busquem "nutrir possibilidades relacionais" (TUNES;TACCA; BARTHOLO JR., 2005, p. 693) para se "promover métodos disciplinados, críticos e reflexivos de questionamento e indagação, [...] essenciais para a aprendizagem e o conhecimento autênticos [...]." (p. 694).

Partindo das práticas relatadas, é possível sugerir que as formas de simplificação metodológica estejam associadas não somente à preocupação do professor com o tempo cronológico, mas também à sua inexperiência em aproveitar o instante presente (Aion), de criar oportunidades de reflexão para o aluno através de questionamentos e indagações sobre o conteúdo que ensina e corrige.

\section{Tempos desperdiçados}

Ao contrário dos tempos poupados, os tempos desperdiçados referemse a uma estrutura temporal que reduz as experiências significativas dos alunos com a língua estrangeira.

Tempo é algo que se gerencia; portanto, podemos desperdiçá-lo algumas vezes. A falta de um plano de aula bem pensado, por exemplo, pode comprometer o tempo de sala de aula em ambas as dimensões: cronológica e não cronológica.

$\mathrm{Na}$ dimensão cronológica, há professores que "dão aulas de improviso, são 'repentistas', sem planejamento prévio do conteúdo." (XAVIER, 2008, p. 190). Outros desperdiçam o tempo com atividades que levariam poucos minutos para serem realizadas. Há ainda situaçôes em que o tempo cronológico é afetado pela cultura "dos poucos minutos para bater o sinal". Professor e alunos encerram suas atividades cinco ou dez minutos antes de o sinal bater por razóes que recaem tanto nos alunos (desinteressados, acostumados etc.) como no professor (tempo exíguo para o início de uma nova atividade). É o que os relatos a seguir ilustram. 
Depois de explicar os exemplos, ainda faltavam quinze minutos para a aula terminar e o professor não havia preparado mais nada para aquela aula. Posso concluir que ele decidiu o que fazer na aula minutos antes da mesma começar, já que não havia previsto o tempo de duração de sua explicação e nem preparado alguma atividade para os alunos fazerem depois da explicação [...] Nesse tempo que sobrou da aula, o professor ficou conversando informalmente com os alunos que, ocasionalmente, tiravam algumas dúvidas de vocabulário. (RONDON; MARIANO; GELSLEICHTER, 2005, p. 156).

Quando ainda faltavam 10 minutos para o término da aula, os alunos já estavam com os seus materiais guardados esperando o sinal tocar. $\mathrm{O}$ professor não reagiu a essa situação, e nos justificou que o desinteresse dos alunos se dava ao fato de eles serem alunos do turno da noite que trabalham durante o dia inteiro. Não concordamos com a postura do professor, pois é seu dever motivar os alunos trazendo atividades mais interessantes e criativas, as quais envolvessem os alunos. (AZEVEDO; MACHADO; PEREIRA, 2004, p. 120).

O tempo linear das ações, do conteúdo e das atividades de aprendizagem precisa ser bem planejado, de tal forma que ele seja aproveitado com maior qualidade, já que existe certo descontentamento entre professores de línguas estrangeiras com relação ao número irrisório de horas-aula por semana na escola básica. É por essa razão, e por outras, que o tempo deve ser considerado precioso, o que não significa dizer que o professor deva "entupir" os alunos de matéria, mas proporcionar, no pouco tempo que se tem, atividades e conteúdos de relevância, planejados para serem explorados num ritmo que considere o tempo de sala de aula em sua plenitude. Isso significa elaborar um projeto de ensino que defina objetivos de aprendizagem claros para as séries em que o professor vai lecionar e um conjunto de atividades e procedimentos de aplicação que possam satisfazer esses objetivos. Suprimir essa etapa é comprometer a ética e a responsabilidade do trabalho docente.

Além do tempo cronológico, o instante presente também sofre com a falta de um planejamento cuidadoso de aula, pois o profissional deixa de refletir sobre as várias possibilidades de explorar metodologicamente um determinado conteúdo, ficando a cargo do livro didático o papel de delimitar o que e como o conteúdo deve ser dado e o tempo a ser destinado a ele.

É necessário um tempo de amadurecimento sobre os conteúdos, as atividades e as suas formas de condução para o professor aprimorar o processo de ensinar e favorecer o aprendizado significativo e propositado da língua estrangeira. Dessa forma, vivenciar o tempo do planejamento é fundamental. 
Sabemos que é na elaboração de planos de aula que o professor estrutura o tempo pedagógico. Nesse momento, ele define perguntas que poderão ser feitas antes e após a atividade, analisa formas de se comunicar e negociar significados na língua estrangeira e reflete sobre a melhor sequência de açôes na aplicação de uma determinada atividade.

O fragmento abaixo é parte de um plano de aula referente à atividade de leitura constante no ANEXO A. O excerto é resultado de um tempo de reflexão sistemática por uma equipe de estagiárias para explorar o texto da atividade (uma história em quadrinhos) e o tópico (quem deve arcar com as despesas de um casal).

\section{Perguntas antes da atividade}

- Faça inicialmente uma pré-leitura do texto, encaminhando as seguintes perguntas para a classe:

1. What type of text is this?

2. Do you read cartoons?

3. What cartoons do you read?

4. Who are the characters of (use aqui o nome de uma história em quadrinhos oferecida por eles)?

5. Who are the characters of this cartoon here?

6. What are the rabbit and the porcupine doing in the cartoon?

(SANTOS; MUCK; XAVIER, 2009, p. 1).

\section{Perguntas após a atividade}

- Após a correção da atividade, encaminhe as seguintes perguntas para a classe para iniciar uma conversa sobre questôes relativas a quem deve arcar com as despesas de um casal:

1. In your opinion, should the boy or the girl pay on a date?

2. What are the possibilities? Converta as respostas dos alunos para o inglês e listeas no quadro. Por exemplo:

- The boy should pay.

- The girl should pay.

- Both should pay their own costs: the boy should pay his costs and the girl should pay her costs.

- Both should split the bill. 
3. If the boy has no money, should the girl pay? Yes or no?

4. If the girl has no money, should the boy pay?

5. If both have money, what are the possibilities?

Insista que a resposta seja dada em inglês. Confirme as respostas dadas (ex.: Yes! Both should pay their own costs Or Both should split the bill). Aponte para essas possibilidades no quadro.

6. Which one is the best option?

(SANTOS; MUCK; XAVIER, 2009, p. 5).

Essa sequência de perguntas permitiu criar um tempo de qualidade em sala de aula ou, melhor dizendo, um tempo reservado para os alunos refletirem, opinarem e discutirem sobre o assunto, buscando maximizar as oportunidades de aprendizagem na língua estrangeira. Portanto, uma aula bem planejada pode trazer uma melhor organização temporal para as açóes do professor, evitando, assim, desperdícios de um tempo precioso no espaço escolar.

\section{Tempos enrijecidos}

É certo que o simples fato de planejar uma aula não assegura, necessariamente, um tempo de qualidade de sala de aula, pois esse tempo não envolve apenas a cronologia das ações pensadas, mas também a vivência dessas ações na prática. Partindo dessa perspectiva, tempos enrijecidos referem-se a uma estrutura temporal fixada no que o professor definiu para as suas ações, sem margem para desvios.

Certas práticas pedagógicas advindas de planejamento reflexivo mostram que o tempo do aluno pode se sobrepor ao tempo do professor, antecipando procedimentos já planejados. São situações inesperadas no olhar do professor, que, às vezes, na sua rigidez, continua no plano das ações que definiu, ignorando o tempo que o aluno quer impor. Para exemplificar, trago um fragmento de um plano de aula com perguntas orais em inglês que foram definidas para serem encaminhadas à classe antes da realização da atividade que consta no ANEXO B. O objetivo foi construir um tempo de conversa com os alunos sobre o filme Autumn in New York.

- Informe aos alunos que eles assistirão a uma cena do filme Autumn in New York (ex.: Now / today you are going to watch a scene of a film, a fragment of a film. The name of the film is Autumn in New York). Escreva o nome do filme no quadro e encaminhe as seguintes perguntas para a classe: 
1. What's the meaning of this title in Portuguese?

2. Have you seen this film already? Did you like it?

3. This is a romantic film. Do you like romantic films?

4. What type of film do you like?

5. As the name of the film indicates, the story happens in autumn. What are the characteristics of autumn? What happens in autumn?

(BAZILIO; BRUGGEMANN; XAVIER, 2009, p. 2).

Assim que o nome do filme havia sido registrado no quadro, como definem os procedimentos acima, um aluno da classe resolveu, espontaneamente, traduzi-lo ('Outono em Nova York'), queimando a próxima etapa que a professora havia planejado, isto é, perguntar à classe o significado do título em português: What's the meaning of this title in Portuguese? (Pergunta 1). Em vez de confirmar a fala do aluno (That's right! "Outono em Nova York"), a professora aprendiz fez prevalecer o seu tempo planejado, encaminhando para a classe a pergunta que já havia sido respondida.

Essa atitude ilustra o controle do professor sobre o tempo que definiu para suas ações. Presa ao seu plano de ensino, ignorou o aluno que havia avançado na mesma direção para a qual ela desejava ir (futuro). O tempo do aluno, no entanto, é visto na contramão da linearidade das ações definidas no plano de aula. Nesse caso, o instante presente (Aion) foi ignorado diante do controle rígido da professora sobre o tempo linear de suas ações (Cronos).

Essa atitude nos remete à necessidade de o professor aprendiz refletir, com a ajuda do professor formador, sobre a estrutura temporal definida no plano de ensino e a estrutura temporal da ação docente, que é marcada pela imprevisibilidade, já que os alunos participam da construção desse tempo. $\mathrm{O}$ tempo vivenciado não deve ser prescrito pelo tempo cronológico das ações pensadas, mas ser orientado por ele.

No tempo enrijecido, é o aluno quem avança no tempo presente, demonstrando seu conhecimento e engajamento na aula. Porém, o tempo do aluno é ignorado por ser um momento que somente ao professor pertence.

No relato a seguir, os exemplos oferecidos pelos alunos (I do not have money; I do not have good grades) são descartados pelo professor, que definiu, para o momento, somente a tradução da sentença "Eu não gosto de chocolate".

Alguns alunos começaram a gerar distúrbios na sala. $O$ professor 1 disse: "gente preste atenção!, isso vai cair na prova". Então ele perguntou: "Como fala: eu não gosto de chocolate", alunos responderam: I do not 
like chocolates. Alguns alunos do fundo começaram a falar sentenças em inglês, por exemplo, I do not have money; I do not have good grades. $\mathrm{O}$ P1 pediu silêncio e não aproveitou esses exemplos dos alunos. (RODRIGUES; FERREIRA, 2006, p. 8).

A antecipação do aluno é, por vezes, manifestada no tempo de fala do professor. Para Xavier (1999), esse tipo de antecipação é um sintoma positivo, pois sugere engajamento dos alunos e o seu interesse em se arriscar para testar e reformular suas hipóteses. Nesse sentido, o professor deve estar preparado para permitir que o seu tempo de fala possa ser roubado, por justa causa, ou que o seu tempo planejado possa sofrer alterações quando os alunos antecipam as ações metodológicas ou as complementam. É dessa forma que os alunos se sentem corresponsáveis pela sua aprendizagem e a de seus colegas, administrando um tempo que deve ser compartilhado com o professor.

Observa-se, portanto, que a ação do professor e a dos alunos seguem no tempo presente visando ao futuro (Cronos), porém, sem sintonia, pelo fato de o professor não aproveitar o momento vivido pelos alunos (Aion).

\section{Considerações para a formação de professores}

Cada professor concebe o tempo de forma diferente, de acordo com a sua maneira de perceber o mundo. Para alguns, o tempo cronológico dos conteúdos e das ações planejadas é mais importante do que o tempo vivenciado no instante presente e, por essa razão, se esquecem de humanizar o tempo, de dar voz e de escutar o que o aluno tem a dizer. São práticas sintonizadas na figura do professor que precisariam ser analisadas e modificadas.

Muitos professores aprendizes de língua inglesa demonstram preocupação com o tempo de completitude das açōes planejadas, esquecendo-se do seu papel de formar alunos críticos, reflexivos, autônomos e cooperativos por meio dessa língua (tempo de plenitude). Por essa razão, o papel do supervisor de estágio é fundamental, pois é ele quem cria momentos de conscientização sobre a estrutura temporal que o professor aprendiz estabelece em sala de aula e o ajuda a entender a necessidade de explorar o instante presente, vivenciá-lo com profundidade e sobrepô-lo ao tempo racional do relógio.

Como Oliveira et al. (2007) salientaram, "[p]ensar no tempo enquanto continuidade nos desafia a pensar nas atividades de sala de aula como momentos de construção, de reflexão, tanto de professores e professoras como de alunos e alunas." (p. 8), em contraposição ao "tempo de cumprir com as obrigações, de realizar atividades que se destinam a preencher a carga horária." (p. 9). 
Para trazer qualidade ao tempo vivencial de sala de aula, importa ao supervisor de estágio promover sessões de reflexão sobre as ações conduzidas pelo estagiário. Nessas sessóes, é preciso que o professor aprendiz:

(a) perceba suas açôes centralizadoras e traga possibilidades de descentralizar-se;

(b) conscientize-se dos efeitos da estrutura temporal de suas açóes na aprendizagem dos alunos;

(c) discuta sobre os conflitos que o tempo lhe traz;

(d) compreenda que a sua ansiedade e a pressa são fatores que encurtam o tempo de reflexão do aluno e de sua própria reflexão;

(e) reflita sobre a necessidade de fazer questionamentos e indagaçōes aos alunos para promover um tempo de amadurecimento do conteúdo;

(f) perceba que o tempo pedagógico não deve ser tratado como um bem de consumo, um tempo que deva ser fornecido aos alunos num pacote de conteúdos e de atividades a serem cumpridos. Essa visão reproduz o tempo na modernidade, em ritmo apressado, orientado para o "futuro", marcado pela ansiedade e com resultados a serem cumpridos em curto prazo. Essa noção de tempo apaga os próprios sentidos do professor, sua percepção sobre o instante presente e a sua reflexão e a dos alunos.

Como desafiar esse tempo que se instala furtivamente na ação do professor aprendiz? Uma alternativa éa reflexão colaborativa e sistemática sobre a ação. Com a ajuda do supervisor, o professor aprendiz pode refletir com profundidade sobre as relaçôes de causa e efeito da estrutura temporal de suas ações. Nesse sentido, uma supervisão in loco e de forma sistemática é fundamental na formação inicial de professores, pois, nem sempre, vemos supervisores na escola. Alguns estão presentes somente na primeira e na última aula do professor aprendiz para poderem comparar esses dois momentos, o que me parece insuficiente para um aperfeiçoamento mínimo da ação docente.

Por outro lado, nem sempre o professor da escola, em seu ritmo frenético de aulas e de atribuiçōes, tem tempo suficiente para apontar e discutir as açōes do professor aprendiz e os seus efeitos na aprendizagem dos alunos. Além disso, há aqueles professores que ainda privilegiam o tempo cronológico, deixando a voz e a reflexão dos alunos em segundo plano. Esses e outros entraves não visam a excluir o professor da escola de sua corresponsabilidade na formação do professor. Ao contrário, há que se enfatizar a presença do supervisor no campo de estágio para o acompanhamento das atividades de 
docência. O papel do supervisor é, entre outras coisas, ajudar o professor aprendiz na autoanálise de suas aulas, na teorização de sua prática e em mudanças significativas no seu fazer.

No entanto, com o aumento da carga horária destinada ao estágio supervisionado nos cursos de Licenciatura (400 horas), o supervisor de estágio se depara com um novo desafio: redimensionar seu tempo de supervisão no espaço escolar. Nem sempre ele pode estar na escola acompanhando o professor aprendiz, mas poderá, num outro tempo e espaço, promover uma análise conjunta de suas aulas com a ajuda da tecnologia. É o caso do vídeo, por exemplo. Em sessões de visionamento de aulas, supervisor de estágio e estagiário(s) podem se encontrar em outro momento e local, que não seja necessariamente o campo de estágio, para discutirem as aulas dadas e os encaminhamentos para as mudanças necessárias para as aulas seguintes.

Independentemente do espaço de reflexão, busca-se uma conscientização do professor aprendiz sobre a estrutura temporal que estabelece para e em sala de aula e as relações dessa estrutura com a qualidade do tempo vivencial entre professor e alunos que se deseja construir.

\section{Referências}

ARAÚJO, A.; SEVERO, C. G. Investigando práticas pedagógicas. Trabalho de conclusão da disciplina Metodologia de Ensino de Inglês. Centro de Ciências da Educação, Universidade Federal de Santa Catarina, Florianópolis, 2006.

AZEVEDO, F.; MACHADO, G. S.; PEREIRA, R. D. P. Relatório final de estágio supervisionado de inglês. Centro de Ciências da Educação, Universidade Federal de Santa Catarina, Florianópolis, 2004.

BAZILIO, D. S.; BRUGGEMANN, D. B.; XAVIER, R. P. Plano da aula 9. Centro de Ciências da Educação, Universidade Federal de Santa Catarina, Florianópolis, 2009. Manuscrito.

BERGER, P. L.; LUCKMANN, T. A construção social da realidade. Petrópolis: Vozes, 2002.

CARVALHO, M. de S. As influências de um roteiro de ensino na prática pedagógica de uma professora de inglês. 2006. 207 f. Dissertação (Mestrado em Educação) - Centro de Ciências da Educaçáo, Universidade Federal de Santa Catarina, Florianópolis, 2006.

DELEUZE, G. Lógica do sentido. 4. ed. São Paulo: Perspectiva, 1998. 
FRAGO, A. V. Tiempos escolares, tiempos sociales: la distribución del tiempo y del trabajo em la enseñanza primaria en España (1838-1936). Barcelona: Ariel, 1998 apud OLIVEIRA, C. E. A. et al. Questôes sobre o tempo no espaço escolar. In: SIMPÓSIO ESPAÇO EDUCAÇÃO, 1., 2007, Juiz de Fora. Anais... Juiz de Fora: Grupo Espaço Educação, 2007. p. 1-12. Disponível em: <http://www.ufjf.br/ espacoeducacao/files/2009/11/cc07_1.pdf>. Acesso em: 5 abr. 2013.

FREIRE, P. Pedagogia da autonomia: saberes necessários à prática educativa. 30. ed. São Paulo: Paz e Terra, 1996.

HOY, D. C. The Time of Our Lives: A Critical History of Temporality. Cambridge (MA): MIT Press, 2009.

JORGE, M. M.; ABELAIRA, P. M. Relatório final de estágio supervisionado de inglês. Centro de Ciências da Educação, Universidade Federal de Santa Catarina, Florianópolis, 2004.

KUMARAVADIVELU, B. The Postmethod Condition: (E)merging Strategies for Second/ Foreign Language Teaching. TESOL Quarterly, v. 28, n. 1, p. 27-48, Spring 1994.

OLIVEIRA, C. E. A. et al. Questôes sobre o tempo no espaço escolar. In: SIMPÓSIO ESPAÇO EDUCAÇÃO, 1., 2007, Juiz de Fora. Anais... Juiz de Fora: Grupo Espaço Educação, 2007.p. 1-12. Disponível em: <http://www.ufjf.br/ espacoeducacao/files/2009/11/cc07_1.pdf>. Acesso em: 5 abr. 2013.

OLIVEIRA, J. M. A. Perversão do presente em currículos nômades: acontecimentos. Pro-Posiçôes, Campinas, v. 18, n. 2, p. 129-144, maio-ago. 2007. Disponível em: <http://mail.fae.unicamp.br/ - proposicoes/textos/53-dossie-oliveirajma.pdf>. Acesso em: 5 abr. 2013.

RODRIGUES, F. F; FERREIRA, C. V. Investigando práticas pedagógicas. Trabalho de conclusão da disciplina Metodologia de Ensino de Inglês. Centro de Ciências da Educação, Universidade Federal de Santa Catarina, Florianópolis, 2006.

RONDON, T. K.; MARIANO, M. H.; GELSLEICHTER, M. Relatório final de estágio supervisionado de inglês. Centro de Ciências da Educação, Universidade Federal de Santa Catarina, Florianópolis, 2005.

SANTOS, C. C.; TAGLIARI, R. V.; PETRIS, V. B. Relatório final de estágio supervisionado de inglês. Centro de Ciências da Educação, Universidade Federal de Santa Catarina, Florianópolis, 2003.

SANTOS, J. M.; MUCK, K. E.; XAVIER, R. P. Plano das aulas 7 e 8. Centro de Ciências da Educação, Universidade Federal de Santa Catarina, Florianópolis, 2009. Manuscrito.

TARDIFF, M. Saberes docentes e formação profissional. 6. ed. Petrópolis: Vozes, 2006. 
TUNES, E.; TACCA, M. C. V. R.; BARTHOLO JR., R. S. O professor e o ato de ensinar. Cadernos de Pesquisa, São Luís, v. 35, n. 126, p. 689-698, set.-dez. 2005. Disponível em: <http://www.scielo.br/pdf/cp/v35n126/a08n126.pdf>. Acesso em: 5 abr. 2013.

XAVIER, R. P. A aprendizagem em um programa temático de lingua estrangeira (Inglês) baseado em tarefas em contextos de $5^{a}$ série do ensino fundamental. 1999. $354 \mathrm{f}$. Tese (Doutorado em Linguística Aplicada) - Instituto de Estudos da Linguagem, Universidade Estadual de Campinas, Campinas, 1999.

XAVIER, R. P. A multiplicidade de percepções na relação entre estagiários, professores, alunos e administradores escolares. In: SEARA, I. C.; DIAS, M. F. S.; OSTETTO, L. E.; CASSIANI, S. (Org.). Práticas pedagógicas e estágios. Florianópolis: Letras Contemporâneas, 2008. p. 177-199. 


\section{ANEXO A \\ Atividade de leitura aplicada à 6⿳亠丷厂 série de uma escola pública}

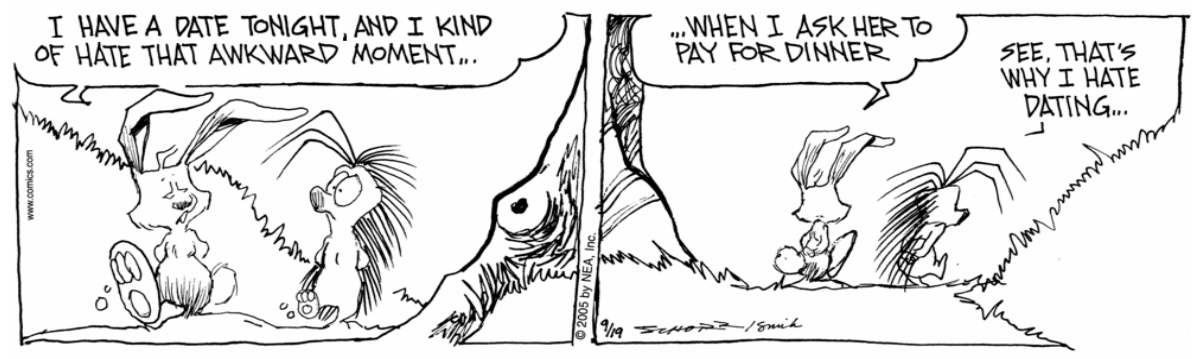

Adapted fromhttp://comics.com/the_grizzwells/2005-09-19/

1. O que o coelho vai fazer hoje à noite?

2. Como ele se sente com relação a isso, à vontade ou desconfortável? Retire do texto o fragmento em inglês que comprova sua resposta.

3. Por que o coelho se sente dessa maneira? O que ele deverá pedir para a namorada?

4. Quando o porco-espinho diz: SEE, THAT'S WHY I HATE DATING..., o que essa frase significa? Complete o significado abaixo:

Tá vendo? É por isso que eu

5. Esse comentário expressa: () uma justificativa.

() um convite.

() um aviso.

6. O porco-espinho entende o sentimento do coelho?

7. O que você acha da situação do coelho? Explique sua resposta.

Atividade elaborada por Juliana Mattos dos Santos e Kátia Eliane Muck. (SANTOS; MUCK; XAVIER, 2009). 


\section{ANEXO B \\ Atividade de compreensão oral aplicada à $7^{\text {a }}$ série de uma escola pública}

Watch a scene of the film Autumn in New York and answer in Portuguese the questions below.

1. Onde o casal está? Num bar?

2. O que você acha que aconteceu com o casal?

() Eles pediram um tempo.

() Eles pediram a separação.

() Eles terminaram o namoro.

3. A iniciativa partiu de quem? Do homem ou da mulher?

4. Por quanto tempo eles estavam juntos?

5. Na sua opinião, quem pode ser a mulher do barco?

6. Você vê alguma relação entre o que aconteceu com o casal e a estação do ano em que a estória acontece (outono)? Qual é a relação?

Atividade elaborada por Darlan da Silva Bazilio e Diogo Bruggemann. (BAZILIO; BRUGGEMANN; XAVIER, 2009).

Recebido em 01/02/2013. Aprovado em 19/04/2013. 